\title{
Glomerulonephritis to Renal Cell Carcinoma: Diagnostic Dilemma with Successful Management of a 8 Year Old Boy
}

\author{
MOHAMMED MARUF-UL-QUADER ${ }^{1}$, BASANA RANI MUHURI ${ }^{2}$, AKM REZAUL KARIM ${ }^{3}$, SHARMIN \\ SULTANA ${ }^{4}$, SAYED MESBAHUL HOQUE ${ }^{5}$
}

\section{Introduction}

Renal cell carcinoma (RCC) is a malignancy thought to arise from epithelial cells of the renal tubule. Although RCC accounts for $2 \%$ to $3 \%$ of all adult malignancies, it occurs rarely in children. ${ }^{1}$ The incidence of this tumor in childhood is estimated to be from $0.1 \%$ to $0.3 \%$ of all neoplasms and from $1.8 \%$ to $6.3 \%$ of all malignant renal tumors. ${ }^{2-5}$ The Third National Cancer Survey on US children reported an incidence of only four cases of RCC per year compared with 117 per year of Wilms' tumor in pediatric age. ${ }^{5}$ Most experience with pediatric RCC limited with case reports or case series consisting of small number of cases. We are reporting a case of 8 year old boy who was prsented with intermittent gross and haematuria proteinurea. Initially suspected as a case of IgA nephropathy. But subsequently diagnosed as RCCClear cell type-a, rare pathological type in children. He was successfully managed by surgery, chemotherapy and radiotherapy.

\section{Case Report}

In December, 2014, Nayon, 8 year old boy admitted in the Department Pediatric Nephrology, Chittagong Medical College \& Hospital for renal biopsy as he was suffering from intermittent gross hematuria following respiratory tract infection for 7 months with occasional mild proteinuria and nephrotic range proteinuria for the last one month. During his initial episode the was treated as a case of post infectious glomerulonephritis. On next episode he visited a senior pediatrician who referred him to a pediatric nephrologist. The patient has no family history of renal

1. Assistant Professor, Pediatric Nephrology, Chittagong Medical College, Chittagong.

2. Associate Professor, Pediatric Nephrology, Chittagong Medical College, Chittagong.

3. FCPS part 2 student, Department of Pediatrics, BSMMU, Dhaka.

4. MD Phase B, Resident, Department of Pediatrics, Chittagong Medical College, Chittagong.

5. Ex Professor, Department of Pediatrics, Chittagong Medical College.

Correspondence: Dr. Mohammed Maruf-ul-Quader, Assistant Professor, Pediatric Nephrology, Chittagong Medical College.

E-mail: marufulquader@yahoo.com disease or of any associated tumor. Between episodes his urine was normal including several routine examination. There was no flank pain, palpable abdominal mass and he was normotensive. Urinary tract infection, idiopathic hypercalciuria, and Systemic Lupus Erythematosus were excluded. Two separate ultrasonograms, five months apart, revealed Glomerulonephritis and normal finding. Urine RBC morphology revealed glomerular origin. He was on follow up as a case of IgA nephropathy. When nephrotic range proteinuria developed, renal biopsy was decided. But just before doing biopsy USG of left kidney revealed cortical thinning with grossly dilated pelvicalycial system and echogenic structure within it.

So biopsy was deferred. In mid January 2015, radical nephrectomy with dissection of pre and paraaortic group of lymphnodes was done. Histopathologically diagnosed as well differentiated renal cell carcinoma (clear cell type) with metastatic deposits in lymphnodes. Liver function test and $\mathrm{S}$. calcium was normal and no there was metastatic focus on chest X-ray. In Pediatric Hematology and Oncology chemotherapy was given. He also received radiotherapy. Till today he is alright.

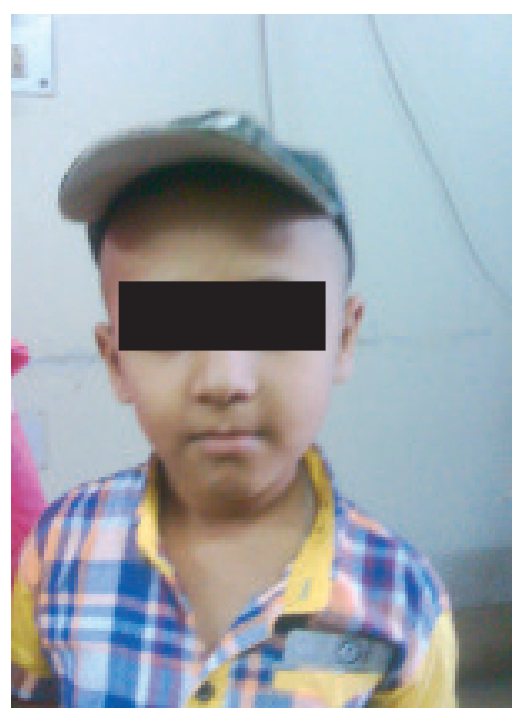

Fig.-1: Master Nayon 3 months after completion of treatment 


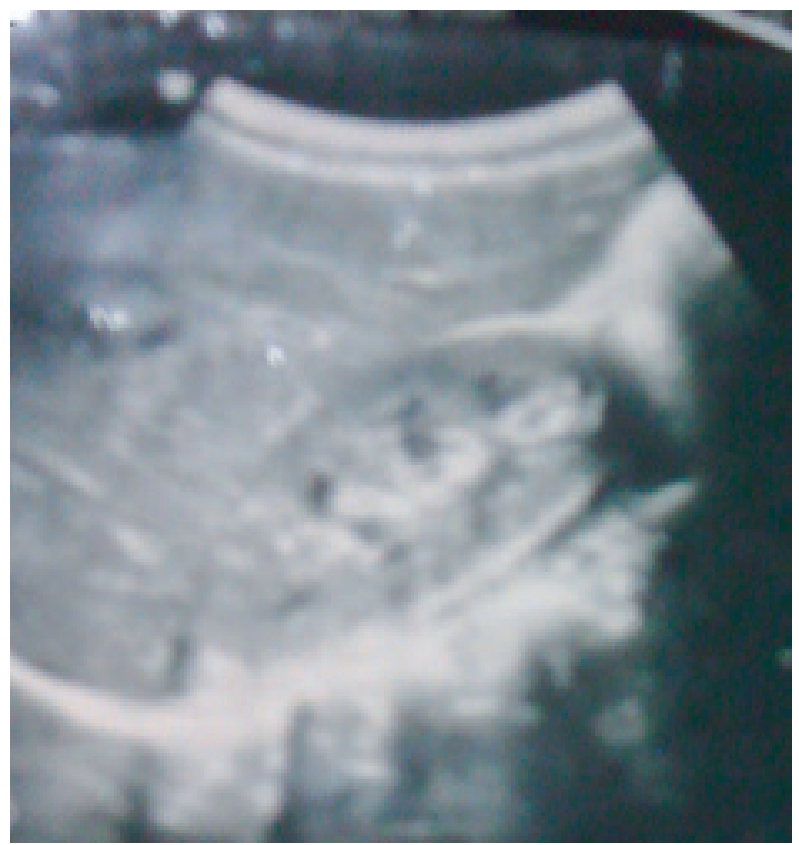

Fig.-2: No mass on USG of left kidney, 12-5-2014

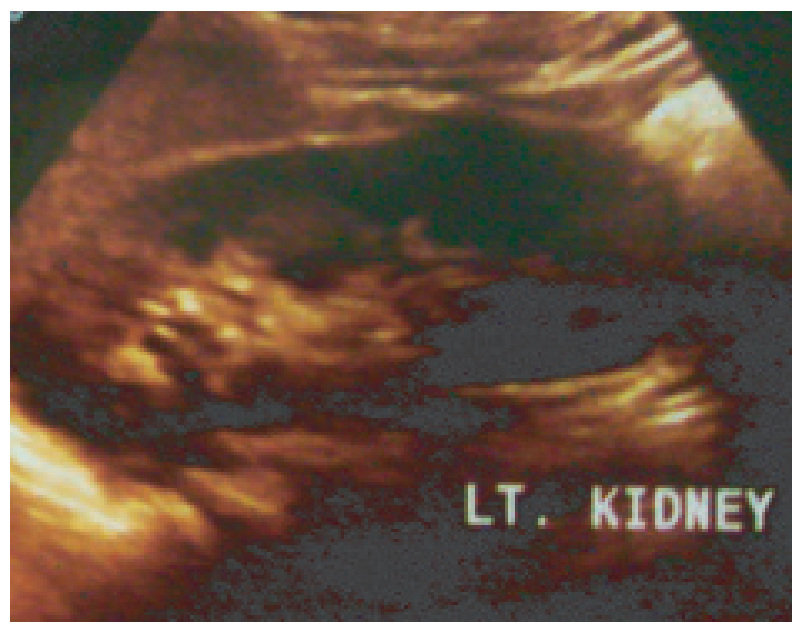

Fig.-3: No mass on USG of left kidney, 10-11-2014

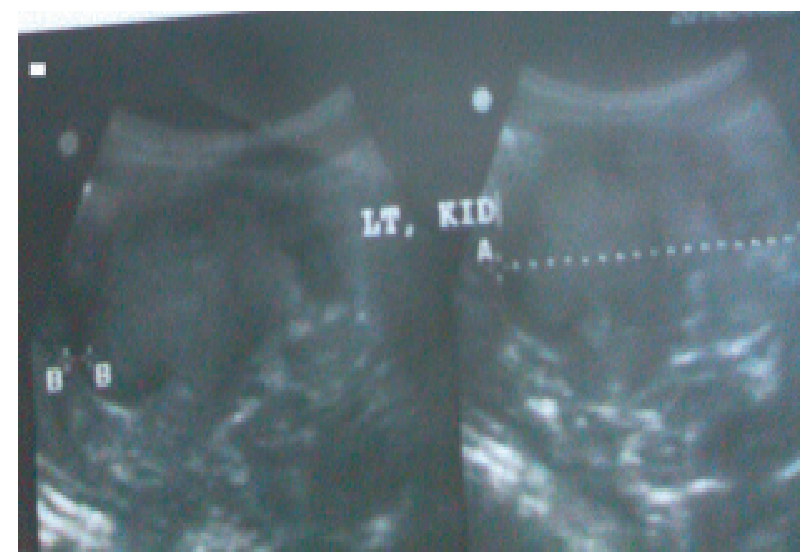

Fig.-4: Large mass on USG of left kidney, 22-12-2014

\section{Discussion}

Pediatric RCC seems to be a distinct clinicopathologic entity compared with adult RCC. Hematuria is the most common initial feature in several study and that the classic triad of hematuria, flank pain, and a palpable abdominal mass is rare in pediatric RCC. 6,7 In this case hematuria was the presentation with proteinuria, even two USG were negative for mass. Paraneoplastic symptoms also are uncommon in pediatric RCC. Mean age at presentation 8-9 years with equal sex distribution, rarely, younger than 1 year of age. Tuberous sclerosis, urogenital malformations, chronic renal failure, neuroblastoma, teratoma with chemotherapy, Saethre-Chotzen syndrome are may be associated with RCC. ${ }^{8,9}$ Right kidney is the predominant site but in this boy left kidney was involved. Histopathology in this boy was well differentiated clear cell type but in children, most cases consist of papillary histologic features, ${ }^{8}$ whereas among the 4 types of RCC (clear cell, papillary, chromophobe, and collecting duct), the clear cell type predominates in adults $(75 \%)$; in younger adults (18-45 years). Cytogenetic and molecular studies have suggested that abnormalities in the Xp11.2 region involving the TFE3 gene might account for a significant proportion of pediatric RCC, with these tumors representing a subset of papillary RCC. Therefore, RCC associated with Xp11.2 translocations TFE3gene fusion is listed as a separate entity in the World Health Organization (WHO) classification of tumors of the urinary system. ${ }^{10}$ Selle $B$ et al ${ }^{11}$ found RCC is predominantly localized. Surgical resection is the mainstay of therapy for RCC given its intrinsic resistance to chemotherapy and radiation therapy, ${ }^{12}$ This boy underwent radical nephrectomy with dissection of pre and para aortic lymphnodes. Tumor size was $8 \times 6 \times 5 \mathrm{~cm}$ with pre and para aortic lymphnode metastasis (T2a N1 Mo, stage III). Patient with distant metastasis may be benefited from chemotherapy, radiotherapy and immunotherapy. MRI/ CT abdomen or bone scan were expensive for his father to see venacaval involvement and distant metastasis. The boy received chemotherapy (doxorubicin, vincristin, cyclophosphamide, etoposide) as per protocol for RCC and also radiotherapy. Absence of distant metastasis was presumed as no bone pain and LFT, CXR, LDH were normal. In regional lymph node-positive, distant metastases-negative $(\mathrm{N}+\mathrm{M} 0)$ $\mathrm{RCC}$, there is a higher survival probability, with a 5year overall survival rate of $75 \% .{ }^{11}$ Since june 2015 the boy is alright. 


\section{Conclusion}

Though RCC is a remote possibility in a child with gross hematuria but it should be kept in mind. Resection of tumor in time is the prognostic factor of event free survival.

\section{References}

1. Zhao WP, Gnarra JR, Liu S. Renal cell carcinoma: Cytogenetic analysis of tumors and cell lines. Cancer Genet Cytogenet.1995;82: 128-39.

2. Riches EW, Griffiths IH, Thachray AC. New growth of kidney and ureter. $\mathrm{Br} \mathrm{J}$ Urol. 1951; 23:297-56.

3. Kumar S, Carr T, Marsden HB. Study of childhood renal tumors using peroxidase conjugated lectins. J Clin Pathol. 1986;39:736-41.

4. Booth CM. Renal parenchymal carcinoma in children. Br J Surg. 1986; 73:313-17.

5. Young JL, Miller RW. Incidence of malignant tumors in US children. J Pediatr. 1975;86: 254-58.

6. Freedman AL, Vates TS, Stewart T. Renal cell carcinoma in children: the Detroit experience. $J$ Urol. 1996;155:1708-10.
7. Altinok G, Kattar MM, Mohamed A. Pediatric renal carcinoma associated with Xp11.2 translocation/TFE3 gene fusions and clinicopathologic associations. Pediatr Dev Pathol. 2005;8:168-80.

8 Carcao MD, Taylor GP, Greenberg ML. Renalcell carcinoma in children: a different disorder from its adult counterpart. Med Pediatr Oncol. 1998;31:153-58.

9 Argani P, Lae M, Ballard ET. Translocation carcinomas of kidney after chemotherapy in childhood. J Clin Oncol. 2006;24:1529-34.

10 Eble JN, Sauter G, Epstein JL. Tumours of the Urinary System and Male Genital Organs. Lyon, France: IARC Press; 2004:37-38.

11 Selle B. Population-Based Study of Renal Cell Carcinoma in Children in Germany, 1980-2005, More Frequently Localized Tumors and Underlying Disorders Compared With Adult Counterparts. Cancer. 2006. 107: 2906-14.

12 Sausville JE. Pediatric renal cell carcinoma, Journal of Pediatric Urology. 2009;5:308-14. 